\title{
Immunization with a dominant-negative recombinant Herpes Simplex Virus (HSV) type 1 protects against HSV-2 genital disease in guinea pigs
}

Richard Brans ${ }^{+1,2}$ and Feng Yao*1

\begin{abstract}
Background: CJ9-gD is a novel dominant-negative recombinant herpes simplex virus type 1 (HSV-1) that is completely replication-defective, cannot establish detectable latent infection in vivo, and expresses high levels of the major HSV-1 antigen glycoprotein D immediately following infection. In the present study, CJ9-gD was evaluated as a vaccine against HSV-2 genital infection in guinea pigs.

Results: Animals immunized with CJ9-gD developed at least 700-fold higher titers of HSV-2-specific neutralization antibodies than mock-immunized controls. After challenge with wild-type HSV-2, all 10 control guinea pigs developed multiple genital lesions with an average of 21 lesions per animal. In contrast, only 2 minor lesions were found in 2 of 8 CJ9-gD-immunized animals, representing a 40-fold reduction on the incidence of primary genital lesions in immunized animals ( $p$ 0.0001). Immunization significantly reduced the amount and duration of viral shedding and provided complete protection against neurological symptoms, while $90 \%$ of mock-immunized animals succumbed due to the severity of disease. Importantly, immunized animals showed no signs of recurrent disease or viral shedding during a 60days observation period after recovery from primary infection, and carried 50-fold less latent viral DNA load in their dorsal root ganglia than the surviving mock-vaccinated controls $(p<0.0001)$.
\end{abstract}

Conclusions: Collectively, we demonstrate that vaccination with the HSV-1 recombinant CJ9-gD elicits strong and protective immune responses against primary and recurrent HSV-2 genital disease and significantly reduces the extent of latent infection.

\section{Background}

Genital herpes is the main cause of genital ulcer disease worldwide and is due to infections with herpes simplex virus (HSV) [1,2]. HSV-2 accounts for most cases of genital herpes [3]. Recent studies indicate that in developed countries HSV-1 has become the main causative agent for primary genital herpes, especially among adolescents, women, and homosexual men [4-7]. The prevalence of HSV-2 in the general population ranges from $10 \%-60 \%$, indicating that genital herpes is one of the most common sexually transmitted diseases $[2,8]$.

\footnotetext{
*Correspondence: fyao@rics.bwh.harvard.edu

1 Department of Surgery, Brigham and Women's Hospital, and Harvard Medical School, Boston, MA 02115, USA

+ Contributed equally

Full list of author information is available at the end of the article
}

After primary genital infection, HSV establishes latent infection in dorsal root ganglia with lifelong persistence, subsequently giving rise to intermittent reactivation and recurrent disease [9]. As the clinical appearance of genital HSV infection varies from unspecific symptoms to typically painful lesions [10], only $10-25 \%$ of people who are seropositive for HSV-2 are aware that they have genital herpes. HSV is intermittently shed from the genital mucosa in the absence of symptoms causing subconscious transmission of disease [11]. Vertical transmission of HSV to neonates is associated with a high mortality rate and a high incidence of neurological sequelae in survivors [12]. In addition, genital herpes has been linked to an increased risk of sexually acquiring and transmitting human immunodeficiency virus (HIV), which can be 
strongly reduced by HSV antiviral therapy $[13,14]$. To date, the treatment and prevention of primary and recurrent disease is limited [15]. Experimental vaccine approaches against genital herpes have included peptides, proteins, killed virus, DNA vaccines, heterologous replicating viral vectors, replication-defective viruses, and attenuated replication-competent viruses [16,17]. Considering the general impact of HSV-1 diseases and rising importance of primary genital herpes caused by HSV-1, a desirable vaccine should be capable of offering effective protective immunity against both HSV subtypes.

A main target for subunit vaccine development has been HSV glycoprotein D (gD), a major antigen on the viral envelope [17]. Subunit vaccines containing gD in combination with an adjuvant appeared to be safe and effective against genital herpes in guinea pigs [18-20], but failed to provide general protection in clinical trials $[21,22]$. Replication-defective viruses lacking functions essential for viral replication or assembly of progeny virus particles have a broad antigenic spectrum and are more efficient than subunit vaccines in eliciting protective immune responses against genital HSV in mice and guinea pigs [23]. However, the use of replication-defective viruses, particularly when used in latently infected individuals, imposes certain risks, as they might regain replication competence in the presence of wild-type virus or reactivate latent wild-type virus infections [24].

To minimize these safety concerns, using the T-REx ${ }^{\mathrm{mm}}$ gene switch technology (Invitrogen, Carlsbad, CA) developed in our laboratory and the dominant-negative mutant polypeptide UL9-C535C of HSV-1 origin binding protein UL9, we generated a novel class of replicationdefective HSV-1 recombinant, CJ83193, which can prevent its own viral DNA replication as well as that of wildtype HSV-1 and HSV-2 in co-infected cells [25,26]. To increase its safety and vaccine efficacy against HSV infections, we recently constructed a CJ83193-derived HSV-1 recombinant C 9 -gD by replacing the essential UL9 gene with an extra copy of the HSV-1 gD (gD1) gene under the control of the tetO-bearing hCMV major immediateearly promoter [27]. We demonstrated that unlike the gD gene controlled by the endogenous promoter whose expression is dependent on viral replication [28], CJ9-gD expresses high-levels of $\mathrm{gD}$ at the immediate-early phase of HSV infection. Moreover, CJ9-gD is completely replication-defective and causes no detectable infection in trigeminal ganglia after ocular or nasal infection in mice [27]. In mice, CJ9-gD induces strong and long-lasting humoral and Th1-associated cellular immune responses against HSV-1 and HSV-2 [27,29]. Immunization with CJ9-gD protects mice against HSV-1 ocular keratitis and guinea pigs against HSV-1 skin disease $[27,30]$ as well as genital herpetic disease caused by wild-type HSV-1 and HSV-2 in mice [29]. Previously, we have shown further that CJ9-gD is a safer and more effective vaccine than non-gD-expressing parental CJ83193 virus against HSV-1 infection $[27,29]$.

The guinea pig model of HSV-2 genital infection offers a unique advantage over the mouse model to investigate the efficacy of candidate HSV vaccine in protection against primary and recurrent HSV-2 genital infection and disease. Specifically, following primary intravaginal infection with HSV-2, guinea pigs develop vesicular lesions resembling those in humans, including development, appearance, and duration of disease. In contrast to mice in which spontaneous reactivation from latent infection rarely occurs in the vaginal tract, guinea pigs undergo episodic spontaneous recurrent infection and disease after recovering from initial genital disease $[31,32]$. In the current report, we investigate whether CJ9-gD can serve as an effective vaccine in protection against both primary and recurrent HSV-2 genital infection and disease in guinea pigs following intravaginal challenge with wild-type HSV-2.

\section{Results}

Induction of HSV-2-specific neutralization antibodies

The ability of CJ9-gD to elicit HSV-2-specific neutralizing antibodies was determined (Fig. 1). The HSV-2-specific neutralization antibody titer was detected in serum from all immunized guinea pigs and increased significantly from the first to the second vaccination $(\mathrm{p}<0.005)$ with a peak titer 3 weeks after the second vaccination of 1400. No HSV-2-specific neutralization antibody was detected in serum from mock-immunized animals at 1:2dilution before challenge. After challenge with the wildtype HSV-2, the neutralization antibody titer in immunized animals increased 2-fold ( $p>0.05$ ) and was 1.5-fold

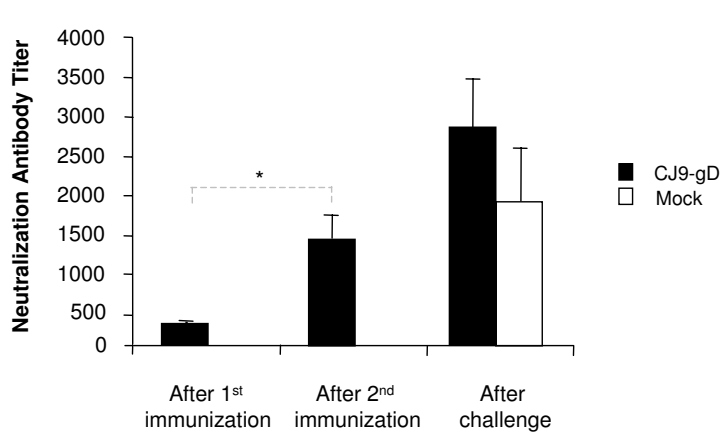

Figure 1 Induction of HSV-2-specific neutralizing antibodies in immunized guinea pigs. Two sets of guinea pigs $(n=8 ; n=10)$ were injected s.c. with $5 \times 10^{6} \mathrm{PFU} /$ animal of CJ9-gD or with DMEM and boosted after 3 weeks. Blood was taken 3 weeks after each immunization and 5 weeks after challenge. After heat inactivation, serum from each animal was assayed separately for HSV-2-specific neutralizing antibody titers on Vero cell monolayers. The results represent average titers \pm SEM. P-value was assessed by Student's t-test $(* p<0.005)$. 
higher than that in mock-immunized controls following challenge.

\section{Reduction of intravaginal replication of challenge HSV-2 in immunized guinea pigs}

Six weeks after the initial immunization, two sets of guinea pigs $(\mathrm{n}=8 ; \mathrm{n}=10)$, which were either mockimmunized $(n=10)$ or immunized with $5 \times 10^{6}$ PFU of Cj9-gD ( $\mathrm{n}=8)$, were challenged intravaginally with wildtype HSV-2 strain MS. To examine the effectiveness of immunization with CJ9-gD against intravaginal replication of challenge HSV-2, vaginal swabs were taken on days 1, 2, 3, 5, 7 and 9 after challenge. As shown in Fig. $2 \mathrm{~A}$, the yields of challenge virus were significantly lower in immunized guinea pigs compared with those in mockimmunized controls from days 1 to 7 ( $\mathrm{p}$-values for days 1 , 2 , and $3<0.05$, p-value for days 5 and $7<0.005$ ), with a

A

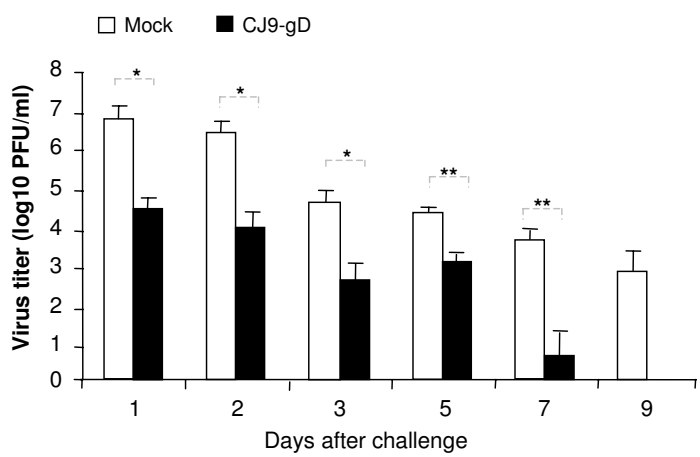

B

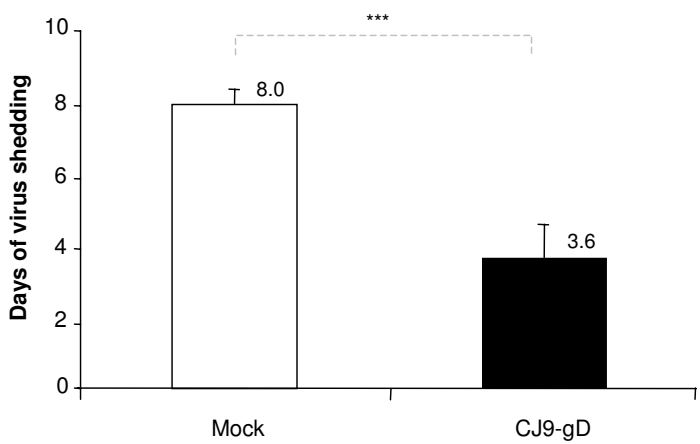

Figure 2 Reduction of challenge HSV-2 vaginal replication in guinea pigs immunized with CJ9-gD. One set of 8 and one set of 10 guinea pigs were inoculated s.c. with either $5 \times 10^{6} \mathrm{PFU} /$ animal of CJ9$\mathrm{gD}$ or DMEM and boosted after 3 weeks. At 6 weeks guinea pigs were challenged intravaginally with $5 \times 10^{5} \mathrm{PFU}$ of HSV-2 strain MS. Vaginal swabs were taken on days 1, 2, 3, 5, 7, and 9 post-challenge. Infectious virus in swab materials was assessed by standard plaque assay on Vero cell monolayers. Viral titers are expressed as the mean \pm SEM in individual vaginal swabs (A). The duration of viral shedding is represented as the mean number of days during which infectious virus was detected in swab materials following challenge \pm SEM (B). P-values were assessed by Student's t-test $\left.{ }^{*} p<0.05,{ }^{* *} p<0.005,{ }^{* * *} p<0.0005\right)$ reduction of 207-fold on day $1(\mathrm{p}=0.036)$ and 220 -fold on day $2(\mathrm{p}=0.012)$. By day 9 no challenge virus was detected in CJ9-gD-immunized guinea pigs, whereas 50\% of mock-immunized animals continued to shed virus at an overall average yield of more than $7.1 \times 10^{2} \mathrm{PFU} / \mathrm{ml}$. Compared with mock-immunized controls, the average duration of viral shedding in immunized guinea pigs decreased markedly from more than 8 days to 3.6 days (Fig. 2B, p < 0.0005).

\section{Protection against primary HSV-2 genital disease in immunized guinea pigs}

After intravaginal challenge with wild-type HSV-2, animals were monitored daily for signs of disease. The development and clinical appearance of lesions caused by challenge virus in mock-vaccinated guinea pigs was consistent with previous observations.

The impact of immunization with CJ9-gD on the incidence of skin lesions is summarized in Fig. 3. All 10 mock-immunized guinea pigs (100\%) developed multiple genital herpes lesions following challenge with wild-type HSV-2. In contrast, only 2 of 8 animals immunized with 5 $\times 10^{6} \mathrm{PFU}$ of CJ9-gD exhibited two mild herpetiform lesions, resulting in an average of 0.5 lesions per immunized animal. In the corresponding control group, an average of 20.6 lesions per mock-vaccinated animal was detected on day 6 post-challenge $(\mathrm{p}<0.0001)$. Thus, the overall incidence of primary herpetic skin lesions in immunized animals was reduced 40-fold compared to mock-immunized controls. Moreover, the two lesions found in the above mentioned immunized guinea pigs were less pronounced and healed off within 2 to 6 days, whereas in mock-immunized animals lesions turned into

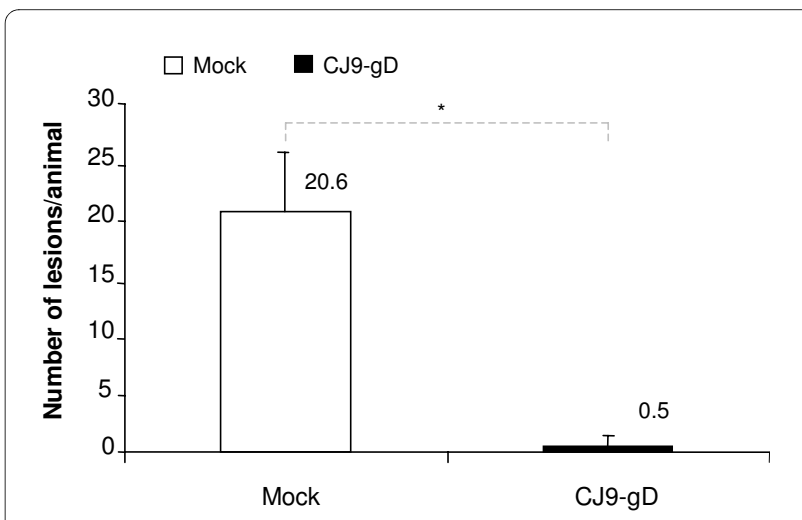

Figure 3 Prevention of primary HSV-2 genital lesions in guinea pigs immunized with CJ9-gD. Mock-immunized and CJ9-gD-immunized guinea pigs described in Fig. 2 were monitored daily for clinical symptoms following challenge with wild-type HSV-2. The average number of lesions per immunized animals was compared with that found in mock-immunized guinea pigs. The indicated values represent the mean number of lesions \pm SD on day 6 post-challenge. P-value was assessed by Student's t-test $\left({ }^{*} p<0.0001\right)$. 


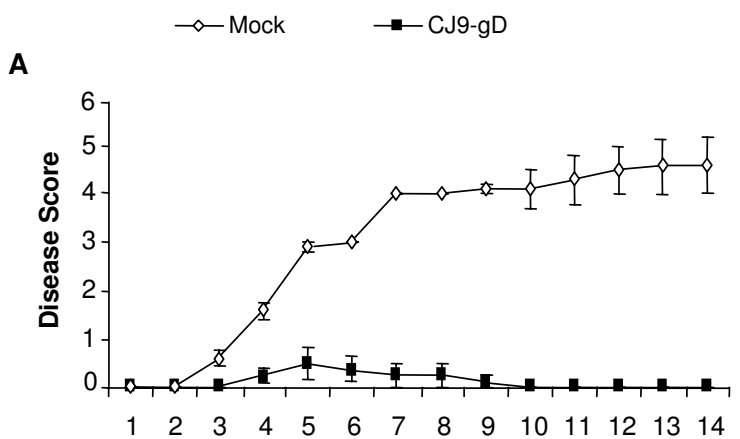

B

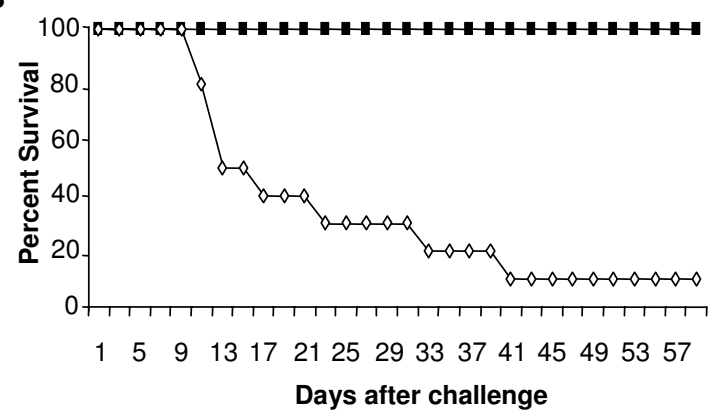

Figure 4 Prevention of primary HSV-2 disease in guinea pigs immunized with CJ9-gD. After challenge with wild-type HSV-2, individual guinea pigs described in legend of Fig. 3 were observed during a 60-day follow-up period for the incidence of genital and disseminated HSV-2 disease using the following score: $0=$ no disease; $1=$ redness or swelling; 2 = a few small vesicles; 3 = several large vesicles; $4=$ several large ulcers with maceration; $5=$ paralysis; and $6=$ death. Presented is the disease score for the first 15 days after challenge (A.) and the percentage of survival until day 60 after challenge (B.).

macerating ulcers with prolonged healing (Fig. 4A) and associated with systemic spreading of virus. All immunized guinea pigs survived the study and showed no signs of neurological illness, whereas 5 of 10 mock-immunized animals $(50 \%)$ were sacrificed by day 14 after challenge due to hind limb paralysis and severity of disease. The mortality rate in this group increased to $90 \%$ by day 41 after challenge (Fig. 4B).

\section{Protection against recurrent HSV-2 infection in immunized guinea pigs}

After recovery from intravaginal challenge with wild-type HSV-2, surviving animals were monitored daily from day 30 to day 60 for signs of recurrent disease. In addition, vaginal swabs were taken daily and assayed for the presence of infectious virus. All immunized animals, and 3 of the 10 mock-immunized controls that survived the first 30 days following challenge with wild-type HSV-2 were monitored for recurrent HSV-2 infection. Two of the mock-immunized animals had recurrent viral shedding between days 30 and 60, whereas one had recurrent lesions. In contrast, no lesions or recurrent viral shedding were detected in immunized guinea pigs (Table 1).

\section{Protection from latent viral infection in immunized guinea pigs}

At day 60 after challenge, 12 lower lumbar and sacral dorsal root ganglia per guinea pig were harvested from all 8 animals immunized with CJ9-gD and the 2 surviving mock-immunized controls. The whole DNA was extracted and tested for latent viral DNA using quantitative real-time PCR. The limit of detection was 5 DNA copies per reaction (correlation coefficient +/- SD: 0.96 $+/-0.016)$. As shown in Fig. 5, the average amount of latent HSV DNA per guinea pig was 50-fold greater in mock-vaccinated controls than in immunized animals (261486 DNA copies vs. 5229 DNA copies, $\mathrm{p} \leq 0.0001$ ).

\section{Discussion}

Although to date no vaccine capable of completely preventing HSV infection has been reported, it is believed that great benefits can be obtained from developing a vaccine that prevents disease with or without partial protection from infection as demonstrated with pertussis and influenza virus vaccines [34]. Our earlier studies demonstrate that immunization with CJ9-gD induces strong and long-lasting HSV-1- as well as HSV-2-specific humoral and Th1- cellular immune responses in mice, leading to a significant reduction in the amount and duration of acute replication of wild-type HSV-1 and HSV-2 after vaginal challenge compared with mockimmunized controls. At an immunization dose of $2 \times 10^{6}$ PFU of CJ9-gD, mice were completely protected from HSV-1 and HSV-2 disease [29]. We were, however, unable to evaluate whether immunization with CJ9-gD is effective in protection against recurrent HSV genital infection and disease in mice. Therefore, in the present report we used guinea pigs to explore the efficacy of immunization with CJ9-gD against HSV-2 primary as well as recurrent genital infection and disease.

Table 1: Prevention of recurrent HSV-2 infection in guinea pigs immunized with CJ9-gD

$\operatorname{Mock}(n=3) \quad$ CJ9-gD $(n=8)$

\begin{tabular}{lll}
\hline Recurrency $^{1}$ & $3 / 3$ & $0 / 8$ \\
Recurrent lesions $^{2}$ & $1 / 3$ & $0 / 8$ \\
Recurrent shedding $^{3}$ & $2 / 3$ & $0 / 8$ \\
\hline
\end{tabular}

1 Overall number of guinea pigs with recurrent lesions and/or recurrent shedding between days 30 and 60 after challenge.

2 Number of guinea pigs with recurrent genital lesion between days 30 and 60 after challenge.

${ }^{3}$ Number of guinea pigs from which virus was detected in vaginal swab material by plaque assay on Vero cell monolayers between days 30 and 60 after challenge. 


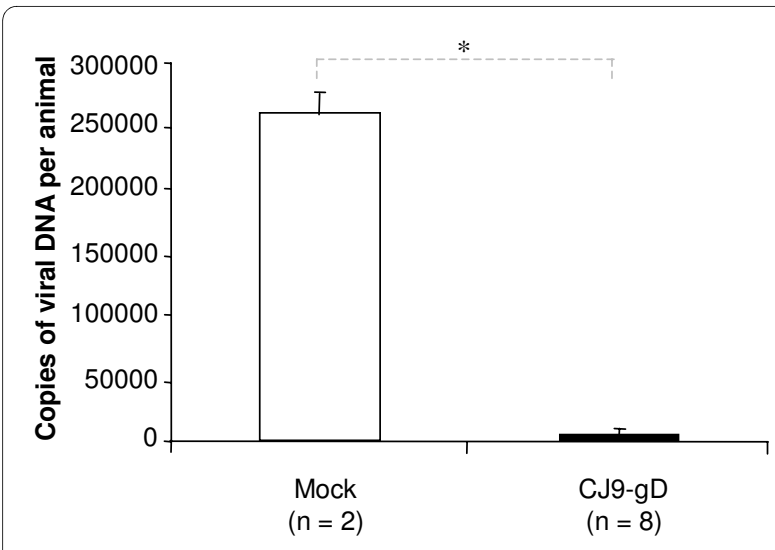

Figure 5 Protection from latent viral infection in guinea pigs immunized with CJ9-gD. Sixty days after challenge, 12 lower lumbar and sacral dorsal root ganglia (DRG) per guinea pig were harvested from all 8 immunized guinea pigs and the 2 surviving mock-immunized controls. The whole DNA was extracted and quantified for the presence of latent viral DNA using quantitative real-time PCR. The amount of viral DNA per guinea pig (A) was determined. The results are indicated as mean values \pm SEM. P-value was assessed by Student's ttest $\left.{ }^{*} p<0.0001\right)$.

We demonstrate that immunization with CJ9-gD at a dose of $5 \times 10^{6} \mathrm{PFU}$ elicits high levels of neutralizing antibodies against HSV-2 in guinea pigs. Titers increased significantly from the first to the second vaccination, indicating a boosting effect. Like in mice [29], immunization with CJ9-gD induced about 7-fold higher neutralization antibody titers in guinea pigs against HSV-1 than HSV-2 ( $<0.0001$ ) (data not shown). In the present study cellular immune responses were not tested due to the lack of sufficient immunological reagents specific for guinea pigs. We did, however, demonstrate in mice that immunization with CJ9-gD elicits strong HSV-specific CD4+ and CD8 + T-cell responses against HSV-1 and in a lesser extent against HSV-2 at levels similar or comparable to those induced by wild-type HSV-1 [27,29]. Given the demonstrated importance for both HSV-specific CD4+ and $\mathrm{CD} 8{ }^{+} \mathrm{T}$ cells in clearance of virus from infected epithelium and in neural tissues in the mouse model of HSV infections [35-40], it is not surprising that HSV-2 crossspecific- $\mathrm{T}$ cell response elicited in $\mathrm{CJ} 9$-gD-immunized guinea pigs plays a critical role in limiting the replication of challenge virus during both primary infection and reactivation from latency.

Immunization with CJ9-gD significantly reduced the amount and duration of wild-type virus replication as well as the number of genital lesions after vaginal challenge with HSV-2 compared with that in mock-immunized guinea pigs. Only 2 of 8 immunized animals developed 2 mild and fast healing herpetiform lesions with no signs of systemic involvement. Morbidity was quite extensive in mock-vaccinated animals with an aver- age of 20.6 lesions per animal, a high incidence of systemic involvement, and a mortality rate of $90 \%$. High mortality rates in mock-vaccinated animals after vaginal challenge with wild-type HSV-2 have been reported by other groups [19,41] and limit the evaluation of recurrences. The extent of disease might be influenced by the viral strain or stock, the viral titer and by the inoculation method used. Despite the extensive disease in mock-vaccinated animals, CJ9-gD provided good protection against genital challenge with wild-type HSV-2 in immunized guinea pigs. Therefore, it is reasonable to anticipate that protection would be more effective should a lower dose of challenge virus or a more gentle inoculation be selected.

In accordance with the protection against primary disease, neither recurrent vaginal shedding of infectious virus nor recurrent genital lesions were found in CJ9-gDimmunized animals. Quantitative PCR analysis shows that the amount of latent HSV DNA in dorsal root ganglia was 50 -fold lower in immunized guinea pigs compared with the 2 mock-immunized guinea pigs that survived following challenge with wild-type HSV-2 ( $<<0.0001$ ). Recall that CJ9-gD cannot establish detectable latent infection in sensory ganglia in mice following ocular or intranasal infection [27] nor in dorsal root ganglia after subcutaneous immunization [29]. The viral DNA detected in dorsal root ganglia of CJ9-gD-immunized guinea pigs after vaginal challenge should be primarily the challenge wild-type HSV-2 viral DNA. Taken together, these results are consistent with observations that a reduced latent infection is associated with a lower incidence of reactivation and recurrent disease $[20,41,42]$.

Several vaccine candidates have been tested in guinea pigs against genital HSV-2 infection. The subunit vaccine gD2/AS04, which contains the HSV-2 major antigen glycoprotein $\mathrm{D}(\mathrm{gD} 2)$ in combination with the adjuvant aluminium hydroxide and 3-O-deacylated-monophosphoryl lipid A (MPL), was effective in prevention of primary and recurrent genital disease in immunized animals following challenge with wild-type HSV-2 $[19,20]$. In phase 3 clinical trials, however, it only provided $73-74 \%$ efficacy in protecting against development of genital herpes disease in HSV-seronegative women [21]. A recent study showed that the replication-defective HSV-2 recombinant dl5-29 was more effective than the HSV-2-gD-based subunit vaccine in inducing HSV-2-specific neutralizing antibodies and $\mathrm{CD}^{+} \mathrm{T}$-cell response in mice [43]. CJ9-gD is an HSV-1 recombinant defective at level of viral DNA replication, and therefore, similar to dl5-29, capable of expressing a broad spectrum of viral antigens. In addition, it has a unique dominant-negative effect on viral replication (UL9-C535C expression) and expresses high levels of the major HSV-1 antigen gD at the immediate- 
early phase of infection [27]. Immunization with CJ9-gD led to 220-fold reduction in the yield of challenge wildtype HSV-2 in genital swabs materials on day 2 post-challenge compared with mock-immunized controls. Noting that immunization with gD2/AS04 resulted in less than 14-fold challenge wild-type HSV-2 (strain MS) viral replication compared with mock-immunized controls on day 2 post-challenge, and all mock-immunized animals survived after recovery from primary disease caused by challenge virus [20], our study suggests that CJ9-gD could potentially be more efficacious than gD2 subunit vaccine against HSV-2 genital disease. It will be interesting to test the vaccine efficacy of gD2/AS04 and CJ9-gD in protecting against HSV-2 genital herpes in the same experimental settings. Moreover, in light of that CJ9-gD expresses high-level of gD, and induction of both effective mucosal and systemic immune responses is likely required for an optimal protection against HSV genital infection, it would be of great interest to investigate the effectiveness of CJ9-gD in induction of humoral and T-cell immunity following different routes of immunization and whether the efficacy of CJ9-gD in eliciting mucosal immune response can be enhanced by $\mathrm{gD}$ subunit prime/CJ9-gD boost regimen involving combination of mucosal and systemic immunization [44-46].

Many type-common and type-specific antibodies as well as $\mathrm{T}$ cell epitopes have been identified against various HSV-1 and HSV-2 proteins. Mice immunized with Cj9-gD develop stronger humoral and cellular immune responses against HSV-1 than against HSV-2, and are significantly better protected against genital infection with HSV-1 than with HSV-2 [29]. These findings are in agreement with the previous reports that in rodents HSV vaccines are generally less effective in prevention of heterotypic HSV infection than homotypic infection $[47,48]$. Combined with observations that humans who were previously infected with HSV-2 are less likely to experience re-infection with a heterologous strain of HSV-2 than individuals with prior HSV-1 infection [4953], it is reasonable to believe, that a CJ9-gD-like dominant-negative HSV-2 recombinant would be more effective in prevention of genital HSV-2 infection than the HSV-1 recombinant CJ9-gD. This HSV-2 recombinant is currently being devised.

\section{Conclusions}

We demonstrate that immunization with a replicationdefective and dominant-negative HSV-1 recombinant Cj9-gD expressing high levels of gD can induce strong cross-protective immunity against primary and recurrent HSV-2 genital infection and disease in guinea pigs. We show further that the latent viral load of challenge wildtype HSV-2 is significantly reduced in immunized guinea pigs compared with the mock-immunized controls. Col- lectively, CJ9-gD represents a new class of HSV-1 recombinant, which is avirulent, unable to establish detectable latent infection in vivo, and serves as an effective vaccine against genital HSV infection and disease in both mice and guinea pigs.

\section{Methods}

Animals

Female Hartley guinea pigs (300-350 g) were obtained from Charles River Breeding Laboratories (Wilmington, MA). The described animal experiments were conducted according to the protocols approved by the Harvard Medical Area Standing Committee on Animals and the American Veterinary Medical Association. The Harvard Medical School animal management program is accredited by the Association for Assessment and Accreditation of Laboratory Animal Care (AAALAC) and meets National Institutes of Health standards as set forth in "The Guide for the Care and Use of Laboratory Animals" (National Academy Press, 1996).

\section{Cells and viruses}

African Green Monkey Kidney (Vero) cells and RUL9-8 cells, a cell line derived from U2OS cells expressing UL9 and the tetracycline repressor (tetR), were grown and maintained in DMEM growth medium as previously described [33].

Wild-type HSV-2 MS strain (ATCC, Manassas, VA) was propagated and plaque assayed on Vero cells. CJ9-gD was derived from CJ83193 by replacing the essential UL9 gene with the HSV-1 gD gene driven by the tetO-containing hCMV major immediate-early promoter [27]. CJ83193 is a replication-defective virus, in which both copies of the HSV-1 ICP0 gene were replaced by DNA sequences encoding the dominant-negative HSV-1 polypeptide UL9-C535C under control of the tetO-bearing hCMV major immediate-early promoter [25]. CJ9-gD was propagated and plaque assayed in RUL9-8 cells.

\section{Immunization and challenge}

One set of 8 guinea pigs and one set of 10 guinea pigs were randomly assigned to 2 groups. Animals were either mock-immunized with DMEM $(\mathrm{n}=10)$ or immunized with $5 \times 10^{6} \mathrm{PFU}$ of CJ9-gD $(\mathrm{n}=8)$ in a volume of $50 \mu \mathrm{l}$ s.c. in the right and left upper flank per guinea pig. On day 21 after primary immunization, animals were boosted. At the same time and one day prior to viral challenge, serum was obtained from saphenous veins and stored at $-80^{\circ} \mathrm{C}$. Six weeks after the initial immunization, the animals were preswabbed with a moist sterile calcium alginate swab (Fisher Scientific, Waltham, MA) and inoculated intravaginally with $100 \mu \mathrm{l}$ of culture medium containing $5 \times 10^{5} \mathrm{PFU}$ of HSV-2 strain MS. Animals were 
kept on their backs with their rear part elevated under the influence of anesthesia for 30-45 min post-infection.

\section{Detection of HSV-2-specific neutralization antibody titers}

Blood was obtained from the saphenous veins and neutralization antibody titers were determined in the presence of complement as described previously $[28,30]$.

\section{Clinical observations}

After challenge with wild-type HSV-2 strain MS, the animals were monitored daily until day 60 . The number of lesions were counted and the progress of disease was scored using a modified method [31]: $0=$ no disease; $1=$ redness or swelling; 2 a few small vesicles; $3=$ several large vesicles; $4=$ several large ulcers with maceration; 5 $=$ paralysis; and $6=$ death .

\section{Assay of acute and recurrent vaginal shedding of challenge virus}

After challenge with wild-type HSV-2 strain MS, vaginal mucosae were swabbed with a moist calcium alginate swab (Fisher Scientific, Waltham, MA) on days 1, 2, 3, 5, 7 and 9. From days 30 to 60 post challenge swabs were taken daily. Swabs were kept in $1 \mathrm{ml}$ DMEM and stored at $-80^{\circ} \mathrm{C}$ until assayed for infectious virus by standard plaque assay on Vero cell monolayers.

\section{Quantitative real-time PCR}

At day 60 after intravaginal challenge with HSV-2 strain MS, 12 lower lumbar and sacral dorsal root ganglia were collected from each of the surviving guinea pigs. Dorsal root ganglia were kept separately in $0.5 \mathrm{ml}$ of normal growth medium and stored at $-80^{\circ} \mathrm{C}$ for further processing. DNA was isolated from each dorsal root ganglion and assayed for viral DNA by quantitative real-time PCR as described previously [27].

\section{Statistical analysis}

For statistical analysis unpaired Student's t-tests were performed.

\section{Abbreviations \\ HSV: Herpes simplex virus; gD: Glycoprotein D.}

\section{Competing interests}

The authors declare that they have no competing interests.

\section{Authors' contributions}

RB participated in designing the experiments, carried out the animal studies, cell culture work, virus assays, and drafted the manuscript. FY developed the HSV-1 recombinant CJ9-gD, designed the experiments, and participated in their coordination and drafting the manuscript. Both authors read and approved the final manuscript.

\section{Acknowledgements}

This work was supported by Public Health Service Grant 5RO1Al05088 from the National Institutes of Health.

\section{Author Details}

'Department of Surgery, Brigham and Women's Hospital, and Harvard Medical School, Boston, MA 02115, USA and 2Department of Dermatology and

Allergology, University Hospital of the RWTH Aachen, 52074 Aachen, Germany

Received: 6 February 2010 Accepted: 3 June 2010

Published: 3 June 2010

References

1. Paz-Bailey G, Ramaswamy M, Hawkes SJ, Geretti AM: Herpes simplex virus type 2: epidemiology and management options in developing countries. Sex Transm Infect 2007, 83(1):16-22.

2. Xu F, Sternberg MR, Kottiri BJ, McQuillan GM, Lee FK, Nahmias AJ, Berman SM, Markowitz LE: Trends in herpes simplex virus type 1 and type 2 seroprevalence in the United States. Jama 2006, 296(8):964-973.

3. Whitley RJ: Herpes simplex encephalitis: adolescents and adults. Antiviral Res 2006, 71(2-3):141-148.

4. Lafferty WE, Downey L, Celum C, Wald A: Herpes simplex virus type 1 as a cause of genital herpes: impact on surveillance and prevention. $J$ Infect Dis 2000, 181(4):1454-1457.

5. Jin F, Prestage GP, Mao L, Kippax SC, Pell CM, Donovan B, Templeton DJ, Taylor J, Mindel A, Kaldor JM, et al.: Transmission of herpes simplex virus types 1 and 2 in a prospective cohort of HIV-negative gay men: the health in men study. J Infect Dis 2006, 194(5):561-570.

6. Roberts CM, Pfister JR, Spear SJ: Increasing proportion of herpes simplex virus type 1 as a cause of genital herpes infection in college students. Sex Transm Dis 2003, 30(10):797-800.

7. Nieuwenhuis RF, van Doornum GJ, Mulder PG, Neumann HA, van der Meijden WI: Importance of herpes simplex virus type-1 (HSV-1) in primary genital herpes. Acta Derm Venereol 2006, 86(2):129-134.

8. Malvy D, Halioua B, Lancon F, Rezvani A, Bertrais S, Chanzy B, Daniloski M, Ezzedine K, Malkin JE, Morand P, et al.: Epidemiology of genital herpes simplex virus infections in a community-based sample in France: results of the HERPIMAX study. Sex Transm Dis 2005, 32(8):499-505

9. Whitley RJ: Herpes simplex virus infection. Semin Pediatr Infect Dis 2002, 13(1):6-11.

10. Corey L, Adams HG, Brown ZA, Holmes KK: Genital herpes simplex virus infections: clinical manifestations, course, and complications. Ann Intern Med 1983, 98(6):958-972.

11. Wald A, Zeh J, Selke S, Warren T, Ryncarz AJ, Ashley R, Krieger JN, Corey L: Reactivation of genital herpes simplex virus type 2 infection in asymptomatic seropositive persons. N Engl J Med 2000, 342(12):844-850.

12. Jones CA: Vertical transmission of genital herpes: prevention and treatment options. Drugs 2009, 69(4):421-434

13. Abu-Raddad LJ, Magaret AS, Celum C, Wald A, Longini IM Jr, Self SG, Corey $\mathrm{L}$ : Genital herpes has played a more important role than any other sexually transmitted infection in driving HIV prevalence in Africa. PLOS ONE 2008, 3(5):e2230

14. Freeman EE, Orroth KK, White RG, Glynn JR, Bakker R, Boily MC, Habbema D, Buve A, Hayes R: Proportion of new HIV infections attributable to herpes simplex 2 increases over time: simulations of the changing role of sexually transmitted infections in sub-Saharan African HIV epidemics. Sex Transm Infect 2007, 83(Suppl 1):i17-24.

15. Whitley RJ, Roizman B: Herpes simplex virus infections. Lancet 2001 , 357(9267):1513-1518

16. Koelle DM, Corey L: Recent progress in herpes simplex virus immunobiology and vaccine research. Clin Microbiol Rev 2003, 16(1):96-113.

17. Stanberry LR: Clinical trials of prophylactic and therapeutic herpes simplex virus vaccines. Herpes 2004, 11(Suppl 3):161 A-169A.

18. Stanberry LR, Bernstein DI, Burke RL, Pachl C, Myers MG: Vaccination with recombinant herpes simplex virus glycoproteins: protection against initial and recurrent genital herpes. J Infect Dis 1987, 155(5):914-920.

19. Bourne N, Bravo FJ, Francotte M, Bernstein DI, Myers MG, Slaoui M, Stanberry LR: Herpes simplex virus (HSV) type 2 glycoprotein D subunit vaccines and protection against genital HSV-1 or HSV-2 disease in guinea pigs. JInfect Dis 2003, 187(4):542-549.

20. Bourne N, Milligan GN, Stanberry LR, Stegall R, Pyles RB: Impact of immunization with glycoprotein D2/AS04 on herpes simplex virus type 
2 shedding into the genital tract in guinea pigs that become infected. $J$ Infect Dis 2005, 192(12):2117-2123.

21. Stanberry LR, Spruance SL, Cunningham AL, Bernstein DI, Mindel A, Sacks S, Tyring S, Aoki FY, Slaoui M, Denis M, et al.: Glycoprotein-D-adjuvant vaccine to prevent genital herpes. N Engl J Med 2002, 347(21):1652-1661.

22. Corey L, Langenberg AG, Ashley R, Sekulovich RE, Izu AE, Douglas JM Jr, Handsfield HH, Warren T, Marr L, Tyring S, et al.: Recombinant glycoprotein vaccine for the prevention of genital HSV-2 infection: two randomized controlled trials. Chiron HSV Vaccine Study Group. Jama 1999, 282(4):331-340.

23. Dudek T, Knipe DM: Replication-defective viruses as vaccines and vaccine vectors. Virology 2006, 344(1):230-239.

24. Koelle DM, Ghiasi H: Prospects for developing an effective vaccine against ocular herpes simplex virus infection. Curr Eye Res 2005, 30(11):929-942.

25. Yao F, Eriksson E: A novel anti-herpes simplex virus type 1-specific herpes simplex virus type 1 recombinant. Hum Gene Ther 1999, 10(11):1811-1818.

26. Yao F, Eriksson E: Inhibition of herpes simplex virus type 2 (HSV-2) viral replication by the dominant negative mutant polypeptide of HSV-1 origin binding protein. Antiviral Res 2002, 53(2):127-133

27. Lu Z, Brans R, Akhrameyeva NV, Murakami N, Xu X, Yao F: High-level expression of glycoprotein $D$ by a dominant-negative HSV-1 virus augments its efficacy as a vaccine against HSV-1 infection. J Invest Dermatol 2009, 129(5):1174-1184.

28. Augustinova H, Hoeller D, Yao F: The dominant-negative herpes simplex virus type 1 (HSV-1) recombinant CJ83193 can serve as an effective vaccine against wild-type HSV-1 infection in mice. J Virol 2004, 78(11):5756-5765

29. Brans R, Akhrameyeva NV, Yao F: Prevention of genital herpes simplex virus type 1 and 2 disease in mice immunized with a gD-expressing dominant-negative recombinant HSV-1. J Invest Dermatol 2009, 129(10):2470-2479.

30. Brans R, Eriksson E, Yao F: Immunization with a dominant-negative recombinant HSV type 1 protects against HSV-1 skin disease in guinea pigs. I Invest Dermatol 2008, 128(12):2825-2832.

31. Stanberry LR, Kern ER, Richards JT, Abbott TM, Overall JC Jr: Genital herpes in guinea pigs: pathogenesis of the primary infection and description of recurrent disease. J Infect Dis 1982, 146(3):397-404.

32. Stanberry LR, Kern ER, Richards JT, Overall JC Jr: Recurrent genital herpes simplex virus infection in guinea pigs. Intervirology 1985, 24(4):226-231.

33. Yao F, Theopold C, Hoeller D, Bleiziffer O, Lu Z: Highly efficient regulation of gene expression by tetracycline in a replication-defective herpes simplex viral vector. Mol Ther 2006, 13(6):1133-1141.

34. Stanberry LR, Cunningham AL, Mindel A, Scott LL, Spruance SL, Aoki FY, Lacey $C J$ : Prospects for control of herpes simplex virus disease through immunization. Clin Infect Dis 2000, 30(3):549-566.

35. Kuklin NA, Daheshia M, Marconi PC, Krisky DM, Rouse RJ, Glorioso JC, Manican E, Rouse BT: Modulation of mucosal and systemic immunity by enteric administration of nonreplicating herpes simplex virus expressing cytokines. Virology 1998, 240(2):245-253.

36. Ghiasi H, Perng G, Nesburn AB, Wechsler SL: Either a CD4(+)or CD8(+)T cell function is sufficient for clearance of infectious virus from trigeminal ganglia and establishment of herpes simplex virus type 1 latency in mice. Microb Pathog 1999, 27(6):387-394.

37. Wakim LM, Jones CM, Gebhardt T, Preston CM, Carbone FR: CD8(+) T-cell attenuation of cutaneous herpes simplex virus infection reduces the average viral copy number of the ensuing latent infection. Immunol Cell Biol 2008, 86(8):666-675.

38. van Lint A, Ayers M, Brooks AG, Coles RM, Heath WR, Carbone FR: Herpes simplex virus-specific CD8 + T cells can clear established lytic infections from skin and nerves and can partially limit the early spread of virus after cutaneous inoculation. J Immuno/ 2004, 172(1):392-397.

39. Johnson AJ, Chu CF, Milligan GN: Effector CD4 + T-cell involvement in clearance of infectious herpes simplex virus type 1 from sensory ganglia and spinal cords. J Virol 2008, 82(19):9678-9688.

40. Zhang X, Chentoufi AA, Dasgupta G, Nesburn AB, Wu M, Zhu X, Carpenter $D$, Wechsler SL, You S, BenMohamed L: A genital tract peptide epitope vaccine targeting TLR-2 efficiently induces local and systemic CD8 + T cells and protects against herpes simplex virus type 2 challenge. Mucosal Immunol 2009, 2(2):129-143.
41. Lekstrom-Himes JA, Pesnicak L, Straus SE: The quantity of latent viral DNA correlates with the relative rates at which herpes simplex virus types 1 and 2 cause recurrent genital herpes outbreaks. J Virol 1998, 72(4):2760-2764.

42. Sawtell NM: The probability of in vivo reactivation of herpes simplex virus type 1 increases with the number of latently infected neurons in the ganglia. J Virol 1998, 72(8):6888-6892.

43. Hoshino Y, Dalai SK, Wang K, Pesnicak L, Lau TY, Knipe DM, Cohen Jl, Straus SE: Comparative efficacy and immunogenicity of replicationdefective, recombinant glycoprotein, and DNA vaccines for herpes simplex virus 2 infections in mice and guinea pigs. J Virol 2005, 79(1):410-418

44. Neutra MR, Kozlowski PA: Mucosal vaccines: the promise and the challenge. Nat Rev Immunol 2006, 6(2):148-158.

45. Gallichan WS, Woolstencroft RN, Guarasci T, McCluskie MJ, Davis HL, Rosenthal KL: Intranasal immunization with CpG oligodeoxynucleotides as an adjuvant dramatically increases $\lg A$ and protection against herpes simplex virus- 2 in the genital tract. $J$ Immunol 2001, 166(5):3451-3457.

46. Tengvall S, Lundqvist A, Eisenberg RJ, Cohen GH, Harandi AM: Mucosal administration of $\mathrm{CpG}$ oligodeoxynucleotide elicits strong CC and CXC chemokine responses in the vagina and serves as a potent Th1-tilting adjuvant for recombinant $\mathrm{gD} 2$ protein vaccination against genital herpes. J Virol 2006, 80(11):5283-5291

47. Boursnell ME, Entwisle C, Blakeley D, Roberts C, Duncan IA, Chisholm SE, Martin GM, Jennings R, Ni Challanain D, Sobek I, et al.: A genetically inactivated herpes simplex virus type 2 (HSV-2) vaccine provides effective protection against primary and recurrent HSV-2 disease. $J$ Infect Dis 1997, 175(1):16-25.

48. Da Costa XJ, Morrison LA, Knipe DM: Comparison of different forms of herpes simplex replication-defective mutant viruses as vaccines in a mouse model of HSV-2 genital infection. Virology 2001, 288(2):256-263.

49. Bryson Y, Dillon M, Bernstein DI, Radolf J, Zakowski P, Garratty E: Risk of acquisition of genital herpes simplex virus type 2 in sex partners of persons with genital herpes: a prospective couple study. I Infect Dis 1993, 167(4):942-946.

50. Mertz GJ, Benedetti J, Ashley R, Selke SA, Corey L: Risk factors for the sexual transmission of genital herpes. Ann Intern Med 1992, 116(3):197-202

51. Looker KJ, Garnett GP: A systematic review of the epidemiology and interaction of herpes simplex virus types 1 and 2. Sex Transm Infect 2005, 81(2):103-107.

52. Schmidt OW, Fife KH, Corey L: Reinfection is an uncommon occurrence in patients with symptomatic recurrent genital herpes. J Infect Dis 1984, 149(4):645-646.

53. Lakeman AD, Nahmias AJ, Whitley RJ: Analysis of DNA from recurrent genital herpes simplex virus isolates by restriction endonuclease digestion. Sex Transm Dis 1986, 13(2):61-66.

doi: $10.1186 / 1471-2180-10-163$

Cite this article as: Brans and Yao, Immunization with a dominant-negative recombinant Herpes Simplex Virus (HSV) type 1 protects against HSV-2 genital disease in guinea pigs BMC Microbiology 2010, 10:163

\section{Submit your next manuscript to BioMed Centra and take full advantage of:}

- Convenient online submission

- Thorough peer review

- No space constraints or color figure charges

- Immediate publication on acceptance

- Inclusion in PubMed, CAS, Scopus and Google Scholar

- Research which is freely available for redistribution 